\title{
Cardiac amyloidosis: case report
}

This case report describes cardiac symptoms as a dominating feature in the clinical picture of newly diagnosed systemic AL amyloidosis. The definitive diagnosis was confirmed microscopically following endomyocardial biopsy. Subsequently, systemic chemotherapy was initiated as the basic treatment for systemic AL amyloidosis.

Keywords: Atrial fibrillation - Cardiac amyloidosis

\section{Introduction}

Amyloidosis is a systemic disease due to a metabolic disorder - impaired protein breakdown with subsequent excessive production of amyloid, an insoluble protein. Then, amyloids are deposited in the extracellular space of various tissues causing harm. Practically any organ in the body may be affected. The cause of amyloid formation and deposition in tissues has not been fully elucidated. The annual incidence is 8 to 10 cases per million populations.

Amyloidosis may be primary (AL), secondary (AA), familial, senile or dialysisrelated, observed in chronic dialysis patients [1]. The primary (AL) form is caused by excessive production of immunoglobulin light chains, usually in multiple myeloma, most frequently affecting the heart, vessels and spleen.

The diagnosis is based on echocardiography, serum analysis, tissue biopsy, cardiac catheterization, late-enhancement magnetic resonance imaging, genetic and other tests. The prognosis of AL amyloidosis depends on the number of affected organs and severity of involvement. The worst prognosis is associated with cardiac involvement, with a median survival in untreated patients of approximately six months from the onset of congestive heart failure [2]. Death occurs as a result of progressive heart failure or sudden cardiac death due to ventricular asystole or electromechanical dissociation [3].
The treatment effectiveness depends on timely diagnosis. Severe organ involvement makes aggressive therapy impossible. The treatment is based on conventional chemotherapy, with primary systemic amyloidosis patients being treated as those with multiple myeloma. An effective alternative for certain patients with AL amyloidosis (involvement of two or, preferably, one organ, no clinically significant heart and kidney damage) is high-dose chemotherapy with subsequent autologous transplantation [4].

\section{Case Report}

A 70-year-old male patient with a history of several heart conditions (myocardial infarction, aortic valve replacement, mitral and tricuspid valve repair) was repeatedly admitted to a local hospital for recurrent heart failure with both pulmonary and systemic congestion and a left ventricular ejection fraction of $30 \%$ due to not fully understood causes.

Admission ECG showed atrial fibrillation with a ventricular rate of $80-100$ beats per minute, a scar in the anterior wall, and no signs of recent ischemic changes as compared with earlier records (Figure 1).

The patient's comprehensive examination also included diagnostic coronary angiography showing insignificant coronary artery disease that did not explain the recurrent heart failure. Echocardiogram image revealed a
František Kováčik*, Miloš Táborský, Martin Hutyra, Ondřej Moravec and Jan Přeček Department of Internal Medicine ICardiology, University Hospital Olomouc, Czech Republic

*Author for correspondence:

Tel: +588443201

E-mail: fkovacik@seznam.cz

Submitted: July 04, 2017

Accepted: October 06, 2017

Published online: October 11, 2017 


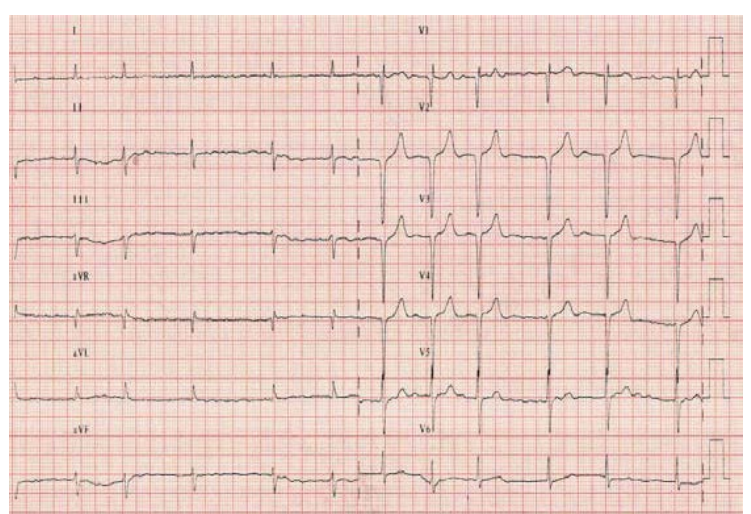

Figure 1: Atrial fibrillation with adequate ventricular response, older changes after $\mathrm{Ml}$ in the past.

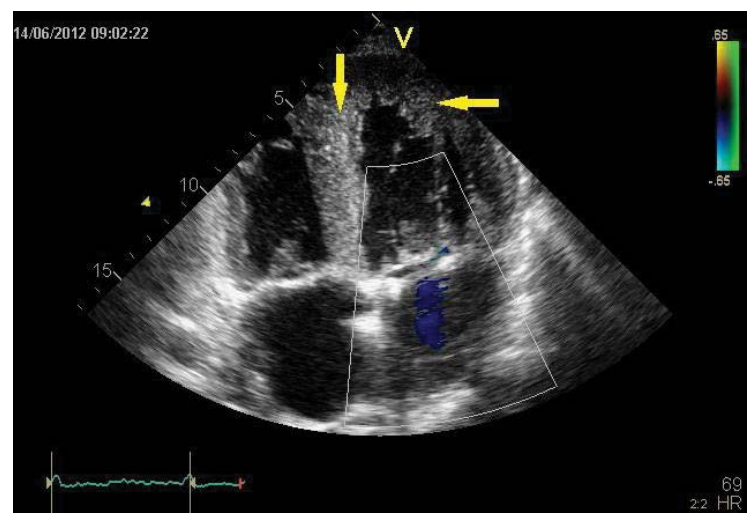

Figure 2: Fine granular appearance of the myocardium-apical four-chamber view.

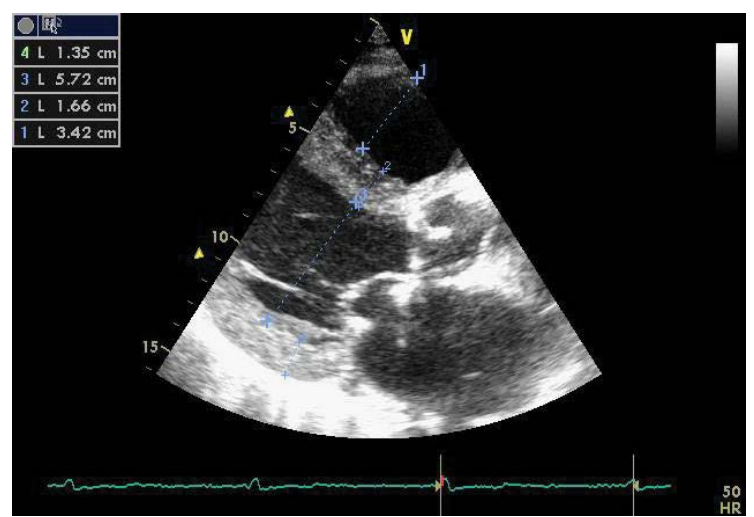

Figure 3: Left ventricular thickening-parasternal long axis view.

significant fine granular appearance of the myocardium, a hypertrophic, slightly dilated left ventricle with diffuse hypocontractility, and restrictive left ventricular filling (Figures 2 and 3).

Given the appearance of the myocardium, the differential diagnosis included a specific etiology of the condition and cardiac amyloidosis was suspected. Magnetic resonance imaging was contraindicated due to the presence of metal clips after previous surgery. There were highly pathological serum levels of kappa
(906 mg/L) and lambda (16.51) free light chains with a pathological kappa/lambda ratio. Neither rectal nor buccal mucosa biopsy confirmed amyloidosis and thus was of no value in the differential diagnosis. Therefore, endomyocardial biopsy was performed, with five samples being obtained from various parts of the left ventricle-the base, apex and outflow tract (Figure 4). In all collected samples, amyloidosis was clearly confirmed (Figure 5).

Given the high initial levels of hs-troponin $\mathrm{T}$ $(1.5 \mu \mathrm{g} / \mathrm{L}$ ), NT-proBNP (above 30,000 $\mathrm{ng} / \mathrm{L}$ ) and demonstrated amyloid infiltration of the myocardium as significant predictive factors for survival, the patient's prognosis was rather unfavorable. Drugs for heart failure were up-titrated to the maximum tolerated dose. Rate control in permanent atrial fibrillation was enhanced and oral anticoagulation therapy with warfarin was continued. After the acute decompensated heart failure was stabilized, systemic chemotherapy was begun. With respect to pre-existing renal insufficiency

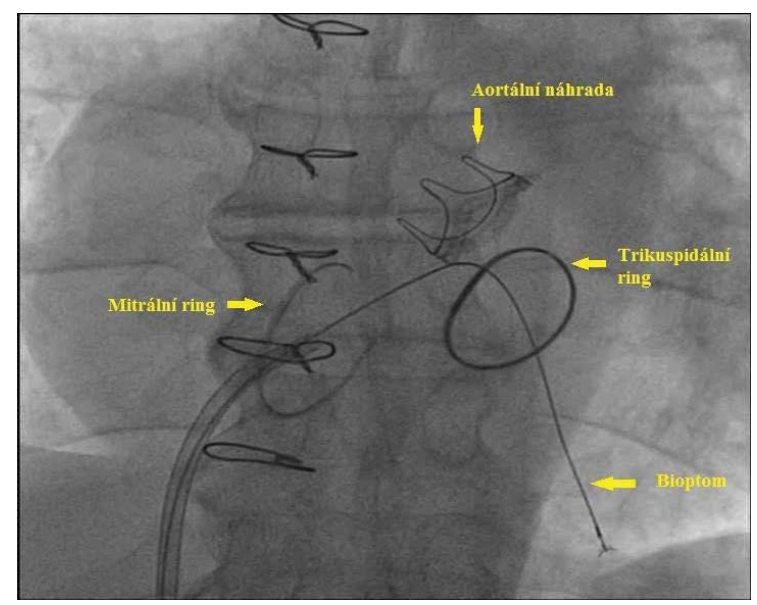

Figure 4: Endomyocardial biopsy: right femoral vein approach; Cook flexible myocardial biopsy forceps introduced through the tricuspid ring into the right ventricle, 5 samples collected from various parts of the right ventricle.

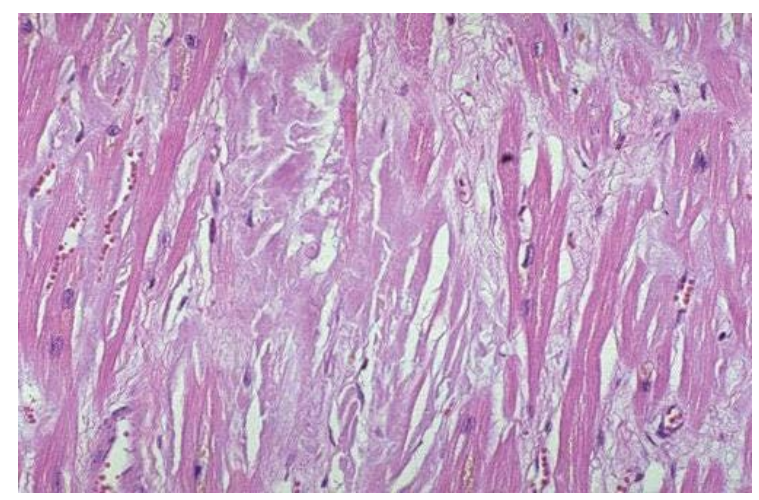

Figure 5: Histologically confirmed amyloid deposits (light pink) between myocardial fibers. 
and a tendency towards cardiac decompensation, VD chemotherapy regimen was selected with reduced dexamethasone doses (Velcade $2.8 \mathrm{mg}$ i.v. on days 1, 8 and 15; dexamethasone $20 \mathrm{mg}$ tablet once a week). After 2 chemotherapy cycles, the patient died of cardiac arrest in the terminal phase of refractory cardiac failure.

\section{Discussion}

Amyloidosis is a rare condition characterized by extracellular deposition of protein fibers, the so-called amyloids. The target organs for amyloid deposits are especially the kidney, heart, nerves, gastrointestinal tract and liver.

The diagnosis of systemic AL amyloidosis with myocardial involvement is based on echocardiography. Frequently, wall thickening is incorrectly referred to as hypertrophy which may potentially lead to the wrong diagnosis of hypertensive heart disease or hypertrophic cardiomyopathy.

Another suitable noninvasive imaging method for detecting amyloids in the myocardium is magnetic resonance imaging. When combined with late gadolinium enhancement, it has a sensitivity of $87 \%$ $[5,6]$. Despite the wide range of possibilities offered by magnetic resonance imaging, a more extensive clinical use of the method is limited by its decreased availability and costly tests. The gold standard for the diagnosis is histological detection of amyloids.

The therapy for AL amyloidosis with cardiac involvement is aimed at treating congestive heart failure and preventing progression of amyloid deposits.

The treatment of $\mathrm{AL}$ amyloidosis is based on conventional chemotherapy as in multiple myeloma. "Suitable" patients may be treated with highdose chemotherapy with autologous stem cell transplantation. However, according to Autologous Stem Cell Transplantation (ASCT) Versus Oral Melphalan and High-Dose Dexamethasone in Patients with AL (Primary) Amyloidosis. A Prospective Randomized Trial, the treatment outcome was not better than that in conventional chemotherapy [7].

The prognosis is influenced by the success of hematological treatment, with remission rates of 40$60 \%$. In the absence of multiorgan involvement, a heart transplant is possible, being the only option allowing potential curative therapy [8].

\section{Conclusion}

The case report points out the importance of performing endomyocardial biopsy in the diagnosis of cardiac amyloidosis in case of negative biopsy results in other areas typical for amyloidosis.

\section{Executive summary}

This case report describes cardiac symptoms as a dominating feature in the clinical picture of newly diagnosed systemic AL amyloidosis.

The definitive diagnosis was confirmed microscopically following endomyocardial biopsy. Subsequently, systemic chemotherapy was initiated as the basic treatment for systemic AL amyloidosis.

\section{References}

1. Vojáček J, Kettner J. Klinická kardiologie. Vydání. 12: 493-495 (2012).

2. Kyle RA, Gertz MA. Primary systemic amyloidosis: clinical and laboratory features in 474 cases. Semin. Hematol. 32: 45-59 (1995).

3. Kristen AV, Dengler TJ, Hegenbart U, et al. Prophylactic implantation of cardioverter-defibrillator in patients with severe cardiac amyloidosis and high risk for sudden cardiac death. Heart. Rhy. 5: 235-240 (2008).

4. Adam Z, Krejčí M,Vorlíček J. a kolektiv, Hematologie-Přehled maligních hematologických nemocí. Vydáni. 6: 254-255 (2008).
5. Raymond Y, Rodney HF. Cardiovascular Magnetic Resonance in Cardiac Amyloidosis. Circulation. 111: 122-124 (2005).

6. Falk RH. Cardiac amyloidosis. Circulation. 124: 1079-1085 (2011).

7. Jaccard A, Moreau P, Leblond V, et al. Myélome Autogreffe (MAG) and Intergroupe Francophone du Myélome (IFM) Intergroup, High-dose melphalan versus melphalan plus dexamethasone for AL amyloidosis. N. Engl. J. Med. 357(11): 1083-1093 (2007).

8. Jan $\mathrm{K}$, Lenka Š, Petr $\mathrm{H}$, et al. Srdeční transplantace následovaná transplantací autologních kmenových buněk pro srdeční selhání na podkladě AL amyloidózy. Vydáni. 10: 152 (2010). 